\title{
Singlet oxygen inactivates protein tyrosine phosphatase-1B by oxidation of the active site cysteine
}

\author{
Claudia von Montfort', Victor S. Sharov³, \\ Sabine Metzger², Christian Schöneich ${ }^{3}$, \\ Helmut Sies ${ }^{1,2}$ and Lars-Oliver Klotz ${ }^{1, *}$ \\ ${ }^{1}$ Institut für Biochemie und Molekularbiologie I, \\ Heinrich-Heine-Universität Düsseldorf, D-40225 \\ Düsseldorf, Germany \\ ${ }^{2}$ Biologisch-Medizinisches Forschungszentrum, \\ Heinrich-Heine-Universität Düsseldorf, D-40225 \\ Düsseldorf, Germany \\ ${ }^{3}$ Department of Pharmaceutical Chemistry, Center for \\ Neurobiology and Immunology Research, Higuchi \\ Biosciences Center, University of Kansas, Lawrence, \\ KS 66047, USA \\ *Corresponding author
e-mail: larsoliver.klotz@uni-duesseldorf.de
}

\begin{abstract}
Singlet oxygen $\left({ }^{1} \mathrm{O}_{2}\right)$, an electronically excited form of molecular oxygen, is a mediator of biological effects of ultraviolet $A$ radiation, stimulating signaling cascades in human cells. We demonstrate here that ${ }^{1} \mathrm{O}_{2}$ generated by photosensitization or by thermodecomposition of $3,3^{\prime}$ (1,4-naphthylidene)dipropionate-1,4-endoperoxide inactivates isolated protein tyrosine phosphatases (PTPases). PTPase activities of PTP1B or CD45 were abolished by low concentrations of ${ }^{1} \mathrm{O}_{2}$, but were largely restored by post-treatment with dithiothreitol. Electrospray ionization mass spectrometry analysis of tryptic digests of PTP1B exposed to ${ }^{1} \mathrm{O}_{2}$ revealed oxidation of active-site Cys215 as the only cysteine residue oxidized. In summary, ${ }^{1} \mathrm{O}_{2}$ may activate signaling cascades by interfering with phosphotyrosine dephosphorylation.
\end{abstract}

Keywords: oxidative stress; photosensitization; signal transduction; tyrosine phosphorylation; ultraviolet radiation.

Exposure of cells or tissues to ultraviolet (UV) radiation results in the activation of signal transduction pathways. It is now widely accepted that the photochemical generation of reactive oxygen species (ROS) is involved in UV-induced activation of cellular signaling events (Tyrrell, 1996; Scharffetter-Kochanek et al., 1997; Valencia and Kochevar, 2006). ROS generated under the influence of UV radiation under physiological conditions include the superoxide anion and its dismutation product, hydrogen peroxide, as well as singlet oxygen $\left({ }^{1} \mathrm{O}_{2}\right)$, an electronically excited form of molecular oxygen (Klotz, 2002; Mahns et al., 2003).
Singlet oxygen was demonstrated to be a major player in signal transduction events initiated by exposure to UVA (320-400 nm) and to mediate UVA-induced activation of JNK and p38 mitogen-activated protein kinases (Klotz et al., 1999; Buchczyk et al., 2001) or UVA-induced expression of target genes (Grether-Beck et al., 1996; Klotz et al., 2001).

Regarding the mechanism of UV-induced activation of signaling processes, a prominent hypothesis is that ROS generated upon irradiation interrupt cellular regulatory circuits by oxidation of signaling molecules. For example, UV-induced activation of receptor tyrosine kinases (RTKs) such as the ErbB family kinases or the PDGF receptor kinases was proposed to be caused by oxidative inactivation of protein tyrosine phosphatases (PTPases) associated with the respective RTKs, resulting in a loss of negative regulation (i.e., dephosphorylation of activated and tyrosine phosphorylated RTK) and in a net RTK activation (Knebel et al., 1996).

Almost all PTPases known so far harbor a cysteine residue at their active site that is crucial for phosphotyrosine dephosphorylation catalysis (Kolmodin and Aqvist, 2001; Tonks and Neel, 2001). Owing to an unusually low $\mathrm{p} K_{\mathrm{a}}$ value of the active-site cysteine in several PTPases, the prevalent thiolate form renders this residue prone to oxidation (Tonks, 2005). While inhibition of PTPases was in fact demonstrated to occur in cells exposed to hydrogen peroxide (Knebel et al., 1996), peroxynitrite (Takakura et al., 1999) or redox-cycling naphthoquinones (Abdelmohsen et al., 2003; Beier et al., 2006), so far it is not known whether ${ }^{1} \mathrm{O}_{2}$ is capable of inactivating PTPases and thus of eliciting signaling processes at the level of PTPase inhibition.

To test for an interaction between singlet oxygen and isolated PTPases, we employed two different PTPases, the isolated $\mathrm{N}$-terminal region of PTP1B (amino acids 1-322), a non-transmembrane PTPase known to interact with RTKs (Östman and Böhmer, 2001), and the intracellular portion of CD45, a leukocyte-specific membranebound PTPase. These PTPases were exposed to a chemical source of ${ }^{1} \mathrm{O}_{2}$, the 1,4-endoperoxide of naphthalene-1,4-dipropionate $\left(\mathrm{NDPO}_{2}\right)$. The thermolabile endoperoxide releases ${ }^{1} \mathrm{O}_{2}$ and the parent compound, naphthalene-1,4-dipropionate (NDP) with a half-life of $23 \mathrm{~min}$ at $37^{\circ} \mathrm{C}$ (corresponding to a first-order rate constant of $5 \times 10^{-4} \mathrm{~s}^{-1}$ ) and a ${ }^{1} \mathrm{O}_{2}$ yield of $50 \%$, as depicted in Figure 1A (Di Mascio and Sies, 1989; Pierlot et al., 2000). The concentrations of $\mathrm{NDPO}_{2}$ employed in this study (1-10 mM) were previously demonstrated to be non-toxic (Grether-Beck et al., 1996; Pierlot et al., 2000), yielding picomolar steady-state concentrations of singlet oxygen, as calculated from a first-order rate constant of 
A

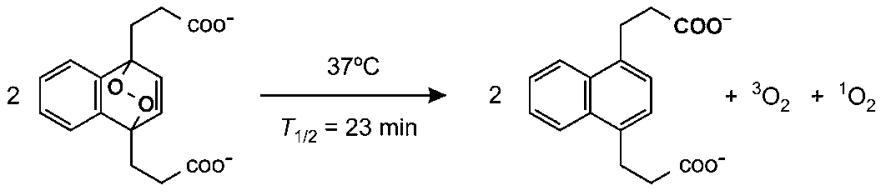

$\mathrm{NDPO}_{2}$

B

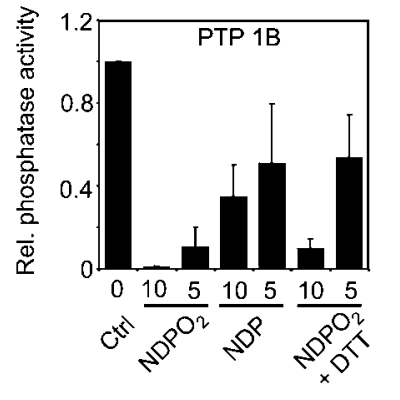

D

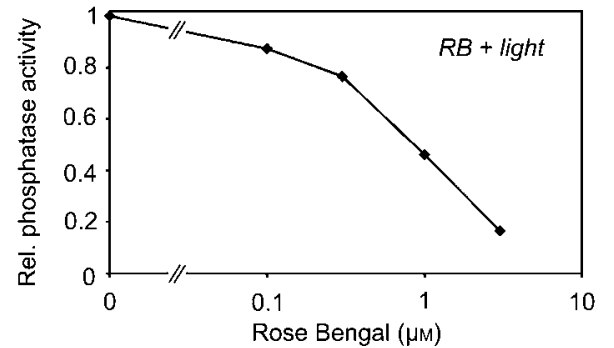

NDP

C

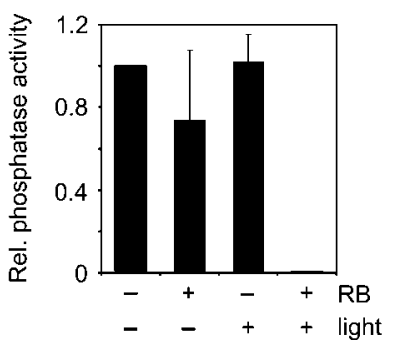

E

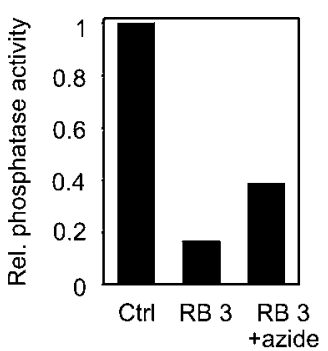

Figure 1 Inactivation of phosphatases by singlet oxygen.

(A) Thermodecomposition of 3,3'-(1,4-naphthylidene)dipropionate-1,4-endoperoxide $\left(\mathrm{NDPO}_{2}\right)$ to form singlet oxygen and 3,3'-(1,4naphthylidene)dipropionate (NDP). $\mathrm{NDPO}_{2}$ was synthesized as previously described (Di Mascio and Sies, 1989). The NDP used was generated by thermodecomposition of $\mathrm{NDPO}_{2}$ at $37^{\circ} \mathrm{C}$ overnight.

(B) Activities of human recombinant PTP1B (amino acids 1-322, corresponding to the N-terminal catalytic domain of the 435-aa fulllength protein; Biomol, Hamburg, Germany) and human recombinant CD45 (cytosolic domain, amino acids 584-1281; Calbiochem, San Diego, CA, USA) after exposure to singlet oxygen. PTP1B $(0.7 \mu \mathrm{M})$ or CD45 $(0.1 \mu \mathrm{M})$ in $50 \mathrm{~mm}$ HEPES (pH 6.8) were left untreated (ctrl) or incubated with $\mathrm{NDPO}_{2}$ or NDP at the concentrations indicated for $10 \mathrm{~min}$ at $34^{\circ} \mathrm{C}$ in a total volume of $50 \mu \mathrm{l}$ and then added to $750 \mu \mathrm{l}$ of assay buffer $\left(20 \mathrm{~mm} p\right.$-nitrophenylphosphate in $50 \mathrm{~mm}$ HEPES buffer, $\mathrm{pH} 6.8,34^{\circ} \mathrm{C}$ ). The subsequent increase in absorbance at $405 \mathrm{~nm}$ (associated with the formation of $p$-nitrophenolate) was monitored, and the formation of $p$-nitrophenol/min calculated using an absorption coefficient of $18000 \mathrm{~m}^{-1} \mathrm{~cm}^{-1}$ after correction for $p$-nitrophenol ionization. Recovery of PTPase activity with DTT was by treatment of PTPases exposed to $\mathrm{NDPO}_{2}$ with $10 \mathrm{~mm}$ DTT (final concentration) for 10 min at $34^{\circ} \mathrm{C}$ prior to activity measurements. Data are given as the mean of three independent experiments \pm SD.

(C) PTP1B was exposed for 10 min to ${ }^{1} \mathrm{O}_{2}$ generated by photosensitization using Rose Bengal (RB) and white light as previously described (Schieke et al., 2004), followed by activity measurements as above. Data are given as the mean of three independent experiments $\pm S D$.

(D) CD45 $(0.05 \mu \mathrm{M})$ was exposed to ${ }^{1} \mathrm{O}_{2}$ generated by photosensitization with white light in the presence of different RB concentrations for $10 \mathrm{~min}$, followed by activity measurements at room temperature as above. Data are the mean of two independent experiments (deviations of single values from the mean were less than $6 \%$ ).

(E) CD45 $(0.05 \mu \mathrm{M})$ was exposed to white light in the presence or absence (Ctrl) of RB ( $3 \mu \mathrm{M})$. Sodium azide (10 mM) was present as indicated. Data are the mean of two independent experiments (deviations from the mean less than $6 \%$ ). Ctrl summarizes controls both with and without azide.

${ }^{1} \mathrm{O}_{2}$ decay in water of $2.4 \times 10^{5} \mathrm{~s}^{-1}$ (Rodgers, 1983). These low ${ }^{1} \mathrm{O}_{2}$ concentrations elicit activation of signaling cascades in cultured cells (Grether-Beck et al., 1996, 2000).

Exposure of isolated phosphatases to $\mathrm{NDPO}_{2}$ resulted in a dramatic loss of phosphatase activity (Figure 1B). Interestingly, NDP also displayed some inhibitory activity. It is proposed that this is due in part to the general affinity of 1,4-derivatives of naphthalene to PTPases. For example, 1,4-naphthoquinone derivatives (including fully substituted naphthoquinones unable to undergo Michael addition reactions) were demonstrated to be potent PTPase inhibitors in cells, as well as of isolated PTP1B in cell-free systems (Melchheier et al., 2005; Beier et al., 2006). Inactivation of PTP1B was also achieved by expo- sure of the protein to ${ }^{1} \mathrm{O}_{2}$ generated photochemically by irradiating PTP1B with white light in the presence of a photosensitizer, Rose Bengal (RB; Figure 1C). Cumulative ${ }^{1} \mathrm{O}_{2}$ formation was similar to that achieved with 1-10 mM $\mathrm{NDPO}_{2}$, as assessed by bleaching of N,N-dimethyl-4nitrosoaniline (Kraljic and El Mohsni, 1978). Neither RB nor white light per se significantly affected PTP1B activity. Similarly, CD45 was inactivated by photochemically generated ${ }^{1} \mathrm{O}_{2}$ in a dose-dependent manner (Figure 1D). Inactivation was significantly attenuated in the presence of azide ions, which are known ${ }^{1} \mathrm{O}_{2}$ quenchers (Figure 1E).

PTPase activities of PTP1B and CD45 exposed to 5 and $1 \mathrm{mM} \mathrm{NDPO}$, respectively, were fully restored to levels observed in the presence of NDP by treatment of oxi- 
A

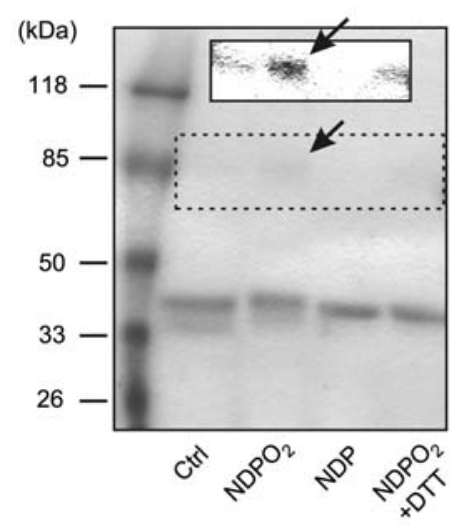

B

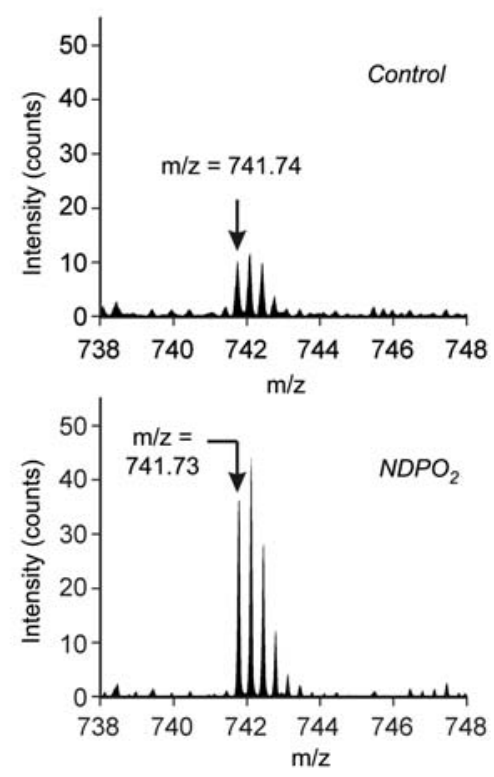

Figure 2 SDS-PAGE and ESI-MS analysis of PTP1B exposed to singlet oxygen.

(A) Following exposure to NDP or $\mathrm{NDPO}_{2}$ as described in the legend to Figure 1 (Ctrl: untreated control), PTP1B was analyzed by electrophoresis on a non-reducing SDS polyacrylamide gel (10\% acrylamide). For lane $4\left(\mathrm{NDPO}_{2}+\mathrm{DTT}\right), \mathrm{NDPO}_{2}$-treated PTP1B was diluted in SDS-PAGE sample buffer containing DTT (final concentration $50 \mathrm{~mm}$ ) prior to electrophoresis. Protein staining was with Coomassie Brilliant Blue G-250 according to Blakesley and Boezi (1977). Arrows and insert: dimeric PTP1B; the insert is an enhanced representation of the boxed gel region and was generated to visualize the faint PTP1B dimer by applying non-linear corrections to the digital image.

(B) PTP1B was left untreated or exposed to $\mathrm{NDPO}_{2}$ as described in the legend to Figure $1 . \mathrm{NH}_{4} \mathrm{HCO}_{3}$ was added to PTP1B solutions to a final concentration of $25 \mathrm{mM}$ and the $\mathrm{pH}$ was adjusted to $7.5-8.5$. Following heat denaturation for 3 min, modified trypsin (Promega, Madison, WI, USA) was added to a trypsin/PTP1B ratio of approximately 1:20 (w/w). After $3 \mathrm{~h}$ of incubation at $37^{\circ} \mathrm{C}$, tryptic digestion was stopped by heat inactivation at $95^{\circ} \mathrm{C}$ for $10 \mathrm{~min}$. Samples were purified and desalted over a $\mathrm{C} 18$ reversed-phase minicolumn (ZipTip C18; Millipore, Bedford, MA, USA) prior to electrospray ionization-mass spectrometry (ESI-MS) analysis. ESI-MS measurements were performed using an ESI-Q-qTOF instrument (QSTAR XL; Applied Biosystems, Darmstadt, Germany) equipped with a nanospray ion source.

dized PTPases with dithiothreitol (DTT), pointing to a thiol modification by ${ }^{1} \mathrm{O}_{2}$ as the cause of inactivation (Figure 1B). Partial restoration was achieved with DTT treatment of PTP1B exposed to $10 \mathrm{~mm} \mathrm{NDPO}$.

Non-reducing SDS-PAGE revealed a slight shift in electrophoretic mobility of PTP1B after treatment with $\mathrm{NDPO}_{2}$ that was not observed with NDP or in $\mathrm{NDPO}_{2}$-treated PTP1B dissolved in electrophoresis sample buffer containing DTT (Figure 2A), implying that ${ }^{1} \mathrm{O}_{2}$ caused an oxidative modification of one or more PTP1B sulfhydryl groups that resulted in changes in molecular mass and/ or charge.

Gel electrophoresis further demonstrated that the dramatic reduction in PTPase activity observed in Figure $1 \mathrm{~A}$ was not due to fragmentation or covalent aggregation of the PTPase. Some PTP1B dimerization was observed in $\mathrm{NDPO}_{2}$-treated samples (Figure 2A, arrows and insert) that was probably due to the formation of a disulfide, because no dimer was observed in the presence of DTT. The extent of dimerization, however, was too little to fully account for the losses in phosphatase activity.

To test for an oxidative modification of the active-site cysteine (Cys215) in PTP1B exposed to ${ }^{1} \mathrm{O}_{2}$, the enzyme was treated with $\mathrm{NDPO}_{2}$, digested with trypsin and analyzed by electrospray ionization mass spectrometry (ESIMS; Figure $2 \mathrm{~B}$ ). The calculated $\mathrm{m} / \mathrm{z}$ value for the tryptic peptide containing Cys215 (PTP1B ${ }^{200-221}$, ESGSLS-
A

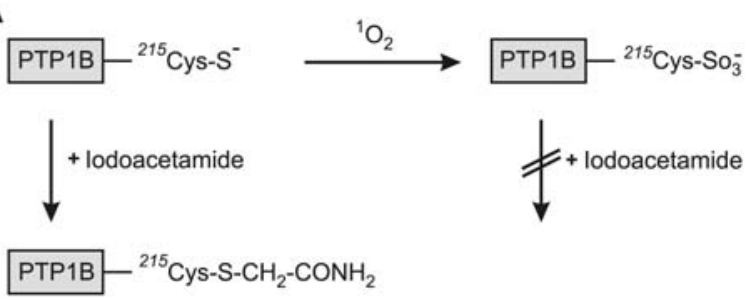

B

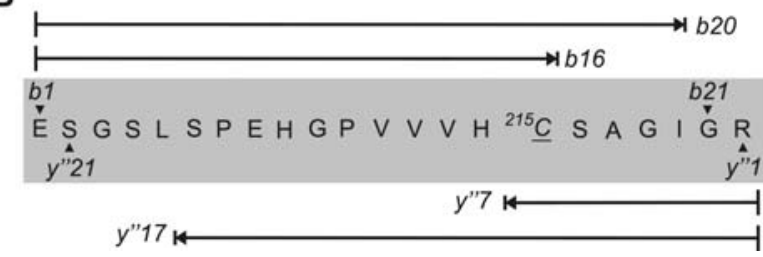

Figure 3 Carboxamidomethylation and tryptic digestion of PTP1B.

(A) Treatment of PTP1B with iodoacetamide carboxymethylates (+57 amu) non-oxidized cysteine residues, but not those cysteines that are oxidized (e.g., to the sulfonic acid form, $+48 \mathrm{amu}$ ), such as by prior exposure of PTP1B to singlet oxygen.

(B) Fragmentation pattern for the peptide PTP1B $200-221$ derived from PTP1B by tryptic digestion, indicating selected $\mathrm{y}^{\prime \prime}-$ and $\mathrm{b}-$ series sequence ions. 
PEHGPVVVH ${ }^{215} \mathrm{CSAGIGR)}$ is 725.7 for the $[\mathrm{M}+3 \mathrm{H}]^{3+}$ ion. In fact, PTP1B ${ }^{200-221}$ was detected as an $[\mathrm{M}+3 \mathrm{H}]^{3+}$ ion at $\mathrm{m} / \mathrm{z} 741.7$ in the $\mathrm{NDPO}_{2}$-treated sample, which corresponds to a difference of 48 atomic mass units (amu) for $[\mathrm{M}+\mathrm{H}]^{+}$and would be in line with the Cys215 sulfonic acid form. Interestingly, however, the same fragment was identified in samples of PTP1B not exposed to $\mathrm{NDPO}_{2}$
(Figure 2B, upper panel), although at significantly lower intensity, pointing to the extraordinary susceptibility of Cys215 to oxidation. To avoid unspecific oxidation of PTP1B during preparation for MS analysis, PTP1B was subjected to non-reducing SDS-PAGE following exposure to $\mathrm{NDPO}_{2}$ or after control treatments and modified with iodoacetamide to prevent oxidation of non-oxidized
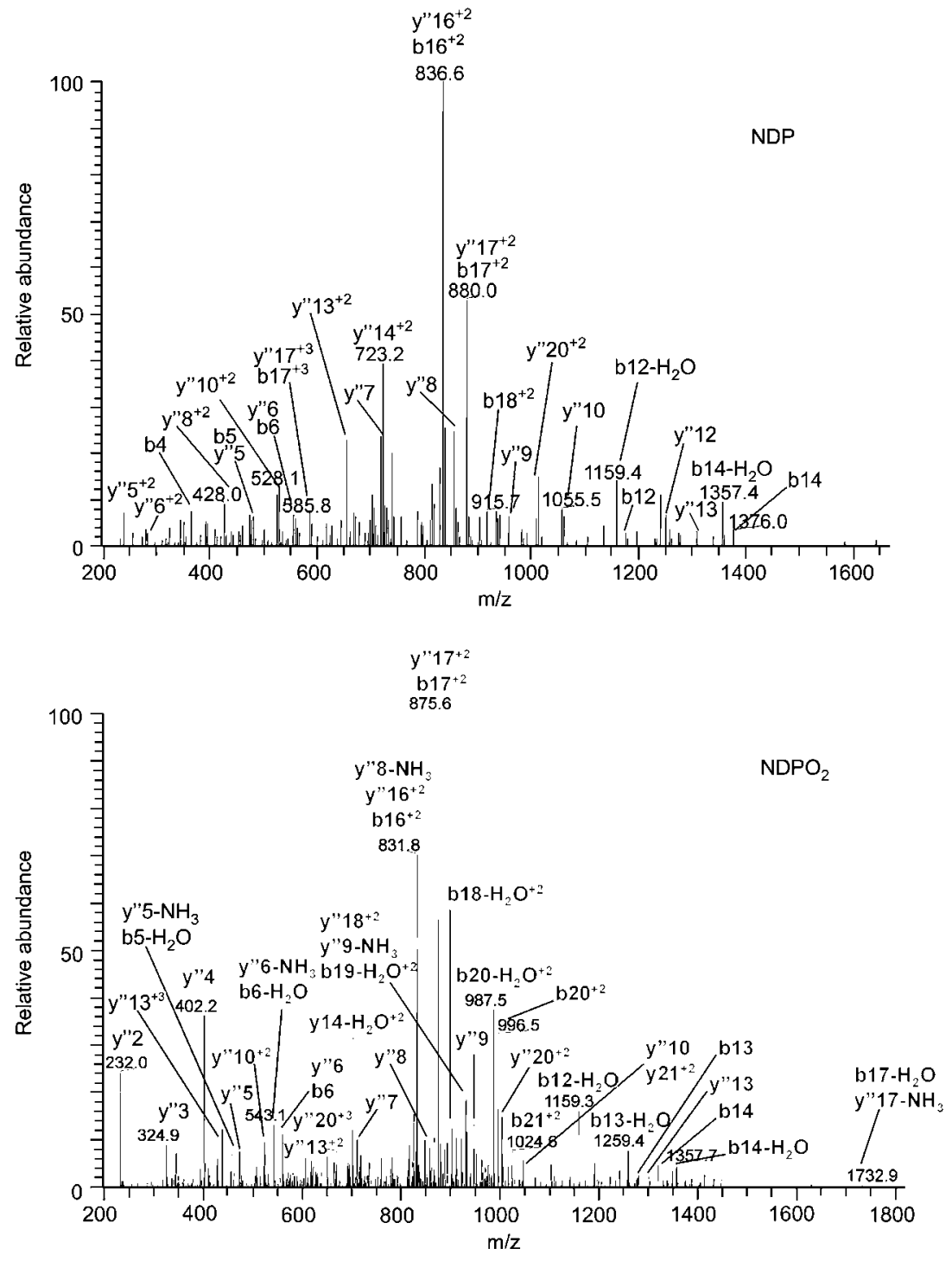

Figure 4 Representative ESI-MS/MS spectra for human PTP1B peptide ESGSLSPEHGPVVVH ${ }^{215}$ CSAGIGR.

Detection of carboxyamidomethylated $(+57 \mathrm{amu})$ or oxidized (+48 amu) Cys215 in samples incubated with NDP and NDPO ${ }_{2}$, respectively. PTP1B (5.4 $\mu \mathrm{M}$ in $50 \mathrm{~mm}$ HEPES buffer, $\mathrm{pH}$ 6.8) was left untreated or was exposed to $5 \mathrm{~mm} \mathrm{NDP}$ or $\mathrm{NDPO}_{2}$ for 10 min at $37^{\circ} \mathrm{C}$ in a total volume of $50 \mu \mathrm{l}$. Samples were subjected to non-reducing SDS-PAGE, followed by staining as described in the legend to Figure 2A. Protein bands of interest were excised from the SDS-PAGE gel, exposed to $5 \mathrm{~mm}$ iodoacetamide for 30 min at room temperature, and processed as previously described (Shevchenko et al., 1996; Sharov et al., 2002). After overnight digestion $\left(16-18 \mathrm{~h}\right.$ at $37^{\circ} \mathrm{C}$ ) with modified trypsin (Promega) at a trypsin/protein ratio of approximately $\left.1: 10 \mathrm{w} / \mathrm{w}\right)$ in $40 \mathrm{mM} \mathrm{NH}_{4} \mathrm{HCO}_{3}$ containing $10 \%(\mathrm{v} / \mathrm{v})$ acetonitrile, the supernatant of the in-gel digest was obtained after bath sonication for $15 \mathrm{~min}$ and short centrifugation. Ingel tryptic digests were submitted to ESI-MS/MS analysis on a ThermoElectron LCQ Classic ion-trap mass spectrometer, equipped with a nanoelectrospray source (ThermoElectron, San Jose, CA, USA). Tryptic peptides were separated on-line on a BioBasic C18 nanoflow column ( $300 \AA, 10 \mathrm{~cm} \times 75 \mu \mathrm{m}, 15-\mu \mathrm{m}$ tip size) (New Objective, Woburn, MA, USA) with the following chromatographic conditions: mobile phase A, $0.1 \%$ formic acid in water; mobile phase B, $0.1 \%$ formic acid in acetonitrile; flow rate, $0.5 \mu \mathrm{l} / \mathrm{min}$, delivered by a MicroTech Xtreme Simple nano-flow pump; gradient profile, from 0 to 5 min held at $10 \% \mathrm{~B}$, then increased to $60 \%$ B within $105 \mathrm{~min}$, and continued at $60 \%$ B for an additional $5 \mathrm{~min}$. After each sample injection $(2 \mu \mathrm{l})$ and MS analysis, the column was washed using a blank run under the same gradient conditions. Peptide sequence analysis was carried out using ThermoElectron Bioworks 3.1 software with the most current non-redundant NCBI protein database downloaded from ftp.ncbi.nlm.nih.gov/blast/db (Ducret et al., 1998). The following modifications were accounted for during the search: oxidation of Met (+16 amu); alkylation of Cys $(+57 \mathrm{amu})$; and oxidation of Cys $(+32 \mathrm{and}+48 \mathrm{amu})$. The XCorr values for the peptides of charge state +3 in the PTP1B/NDP and PTP1B/NDPO ${ }_{2}$ spectra are 3.701 and 3.588 , respectively; $\Delta \mathrm{Cn}$ values are 0.000 . 
cysteine residues during further processing, resulting in carboxamidomethylation of thiol(ate)s but not oxidized cysteinyl residues (Figure 3A). PTP1B bands were excised from the gels, followed by in-gel digestion with trypsin and HPLC-nanoelectrospray ionization-tandem mass spectrometry (LC-ESI-MS/MS).

LC-ESI-MS/MS analysis of the in-gel digests allowed the identification of PTP1B peptides, with up to $79.2 \%$ sequence coverage in a single run at recommended probability scores (XCorr values higher than 1.5, 2.0, and 2.5 for peptides with the charge states of $+1,+2$, and +3 , respectively). The peptide containing Cys215 was detected as $[\mathrm{M}+3 \mathrm{H}]^{3+}$ ions at $\mathrm{m} / \mathrm{z} 744.7$ and 741.7 , representing the peptides with carboxyamidomethyl Cys $(+57$ amu) and cysteic (sulfonic) acid residues (+48 amu), respectively (Figure $4 \mathrm{~A}, \mathrm{~B})$. Our conclusion is based on analysis of the mass differences for sequence ions higher than $\mathrm{y}^{\prime \prime} 7$ and b16 (see Figure 3B for nomenclature). Importantly, alkylated Cys215 (+57 amu) was detected with an acceptable score only for the protein from control samples from untreated or NDP-treated PTP1B. In contrast, the conversion of Cys215 to cysteic acid (+48 amu) was only detected in samples treated with $\mathrm{NDPO}_{2}$. Thus, incubation with $\mathrm{NDPO}_{2}$ induces oxidation of Cys215 to cysteic acid. At this point, we cannot specify whether the reaction of ${ }^{1} \mathrm{O}_{2}$ with Cys215 also leads to sulfenic acid (Cys-SOH; +16 amu) or sulfinic acid $\left(\mathrm{Cys}-\mathrm{SO}_{2} \mathrm{H} ;+32 \mathrm{amu}\right)$, as both products are expected to be very unstable under the experimental conditions. In addition, the formation of a sulfenyl amide that was previously demonstrated to be formed in PTP1B exposed to hydrogen peroxide (Salmeen et al., 2003; van Montfort et al., 2003) cannot be excluded. However, the intermediate formation of Cys215-sulfenic acid or of the corresponding sulfenyl amide would be in line with the fact that recovery of PTPase activity is achieved by exposure to DTT (Figure 1) that is insufficient for reduction of sulfinic and sulfonic acid derivatives of cysteine. It would thus seem that sulfonic acid formation at Cys215 is the result of sequential oxidations of the thiol via sulfenic and sulfinic acids.

For the higher-molecular-weight protein band (Figure 2A, arrows), PTP1B sequence coverage achieved after in-gel digestion was $56.0 \%$, implying that this weak band most probably represents a PTP1B dimer.

Second-order rate constants for the reaction with ${ }^{1} \mathrm{O}_{2}$ are three to four orders of magnitude higher for thiolates of low molecular mass than for the corresponding thiols (Rougee et al., 1988). This may explain why oxidation of PTP1B by ${ }^{1} \mathrm{O}_{2}$ derived from $\mathrm{NDPO}_{2}$ was fairly selective for Cys215 (Lohse et al., 1997). We did not detect any other oxidative modifications in the protein sequence in samples incubated with $\mathrm{NDPO}_{2}$ relative to control samples, except for the partial oxidation of Cys92 to sulfinic acid exclusively in the faint dimeric protein band (data not shown). Partial formation of methionine sulfoxide on Met98, Met258, and Met292 was observed in all samples and may be attributed to protein oxidation during sample preparation, SDS-PAGE or ESI-MS/MS analysis.

In summary, ${ }^{1} \mathrm{O}_{2}$ causes PTPase inactivation by oxidation of the active-site cysteine and may thus elicit signaling effects in cells by interception with tyrosine phosphorylation/phosphotyrosine dephosphorylation equilibria.

\section{Acknowledgments}

This study was supported by Deutsche Forschungsgemeinschaft (Bonn, Germany; Sonderforschungsbereich 503, Project B1). H.S. is a Fellow of the National Foundation for Cancer Research, Bethesda, MD, USA.

\section{References}

Abdelmohsen, K., Gerber, P.A., von Montfort, C., Sies, H., and Klotz, L.O. (2003). Epidermal growth factor receptor is a common mediator of quinone-induced signaling leading to phosphorylation of connexin-43: role of glutathione and tyrosine phosphatases. J. Biol. Chem. 278, 38360-38367.

Beier, J.I., von Montfort, C., Sies, H., and Klotz, L.O. (2006). Activation of ErbB2 by 2-methyl-1,4-naphthoquinone (menadione) in human keratinocytes: role of EGFR and protein tyrosine phosphatases. FEBS Lett. 580, 1859-1864.

Blakesley, R.W. and Boezi, J.A. (1977). A new staining technique for proteins in polyacrylamide gels using Coomassie brilliant blue G250. Anal. Biochem. 82, 580-582.

Buchczyk, D.P., Klotz, L.O., Lang, K., Fritsch, C., and Sies, H. (2001). High efficiency of 5-aminolevulinate-photodynamic treatment using UVA irradiation. Carcinogenesis 22, 879883.

Di Mascio, P. and Sies, H. (1989). Quantification of singlet oxygen generated by thermolysis of 3,3'-(1,4-naphthylidene)dipropionate. Monomol and dimol photoemission and the effects of 1,4-diaazabicyclo[2.2.2]octane. J. Am. Chem. Soc. 111, 2909-2914.

Ducret, A., van Oostveen, I., Eng, J.K., Yates, J.R. III, and Aebersold, R. (1998). High throughput protein characterization by automated reverse-phase chromatography/electrospray tandem mass spectrometry. Protein Sci. 7, 706-719.

Grether-Beck, S., Bonizzi, G., Schmitt-Brenden, H., Felsner, I., Timmer, A., Sies, H., Johnson, J.P., Piette, J., and Krutmann, J. (2000). Non-enzymatic triggering of the ceramide signalling cascade by solar UVA radiation. EMBO J. 19, 5793-5800.

Grether-Beck, S., Olaizola-Horn, S., Schmitt, H., Grewe, M., Jahnke, A., Johnson, J.P., Briviba, K., Sies, H., and Krutmann, J. (1996). Activation of transcription factor AP-2 mediates UVA radiation- and singlet oxygen-induced expression of the human intercellular adhesion molecule 1 gene. Proc. Natl. Acad. Sci. USA 93, 14586-14591.

Klotz, L.O. (2002). Oxidant-induced signaling: effects of peroxynitrite and singlet oxygen. Biol. Chem. 383, 443-456.

Klotz, L.O., Pellieux, C., Briviba, K., Pierlot, C., Aubry, J.M., and Sies, H. (1999). Mitogen-activated protein kinase (p38-, JNK-, ERK-) activation pattern induced by extracellular and intracellular singlet oxygen and UVA. Eur. J. Biochem. 260, 917-922.

Klotz, L.O., Holbrook, N.J., and Sies, H. (2001). UVA and singlet oxygen as inducers of cutaneous signaling events. Curr. Probl. Dermatol. 29, 95-113.

Knebel, A., Rahmsdorf, H.J., Ullrich, A., and Herrlich, P. (1996). Dephosphorylation of receptor tyrosine kinases as target of regulation by radiation, oxidants or alkylating agents. EMBO J. 15, 5314-5325.

Kolmodin, K. and Aqvist, J. (2001). The catalytic mechanism of protein tyrosine phosphatases revisited. FEBS Lett. 498, 208-213.

Kraljic, I. and El Mohsni, S. (1978). A new method for the detection of singlet oxygen in aqueous solutions. Photochem. Photobiol. 28, 577-581. 
Lohse, D.L., Denu, J.M., Santoro, N., and Dixon, J.E. (1997). Roles of aspartic acid-181 and serine-222 in intermediate formation and hydrolysis of the mammalian protein-tyrosinephosphatase PTP1. Biochemistry 36, 4568-4575.

Mahns, A., Melchheier, I., Suschek, C.V., Sies, H., and Klotz, L.O. (2003). Irradiation of cells with ultraviolet-A (320-400 nm) in the presence of cell culture medium elicits biological effects due to extracellular generation of hydrogen peroxide. Free Radic. Res. 37, 391-397.

Melchheier, I., von Montfort, C., Stuhlmann, D., Sies, H., and Klotz, L.O. (2005). Quinone-induced Cdc25A inhibition causes ERK-dependent connexin phosphorylation. Biochem. Biophys. Res. Commun. 327, 1016-1023.

Östman, A. and Böhmer, F.D. (2001). Regulation of receptor tyrosine kinase signaling by protein tyrosine phosphatases. Trends Cell Biol. 11, 258-266.

Pierlot, C., Aubry, J.M., Briviba, K., Sies, H., and Di Mascio, P. (2000). Naphthalene endoperoxides as generators of singlet oxygen in biological media. Methods Enzymol. 319, 3-20.

Rodgers, M.A.J. (1983). Solvent-induced deactivation of singlet oxygen: additivity relationships in nonaromatic solvents. J. Am. Chem. Soc. 105, 6201-6205.

Rougee, M., Bensasson, R.V., Land, E.J., and Pariente, R. (1988). Deactivation of singlet molecular oxygen by thiols and related compounds, possible protectors against skin photosensitivity. Photochem. Photobiol. 47, 485-489.

Salmeen, A., Andersen, J.N., Myers, M.P., Meng, T.C., Hinks, J.A., Tonks, N.K., and Barford, D. (2003). Redox regulation of protein tyrosine phosphatase $1 \mathrm{~B}$ involves a sulphenylamide intermediate. Nature 423, 769-773.

Scharffetter-Kochanek, K., Wlaschek, M., Brenneisen, P., Schauen, M., Blaudschun, R., and Wenk, J. (1997). UVinduced reactive oxygen species in photocarcinogenesis and photoaging. Biol. Chem. 378, 1247-1257.
Schieke, S.M., von Montfort, C., Buchczyk, D.P., Timmer, A., Grether-Beck, S., Krutmann, J., Holbrook, N.J., and Klotz, L.O. (2004). Singlet oxygen-induced attenuation of growth factor signaling: possible role of ceramides. Free Radic. Res. 38, 729-737.

Sharov, V.S., Galeva, N.A., Knyushko, T.V., Bigelow, D.J., Williams, T.D., and Schöneich, C. (2002). Two-dimensional separation of the membrane protein sarcoplasmic reticulum Ca-ATPase for high-performance liquid chromatography-tandem mass spectrometry analysis of posttranslational protein modifications. Anal. Biochem. 308, 328-335.

Shevchenko, A., Wilm, M., Vorm, O., and Mann, M. (1996). Mass spectrometric sequencing of proteins silver-stained polyacrylamide gels. Anal. Chem. 68, 850-858.

Takakura, K., Beckman, J.S., Millan-Crow, L.A., and Crow, J.P. (1999). Rapid and irreversible inactivation of protein tyrosine phosphatases PTP1B, CD45, and LAR by peroxynitrite. Arch. Biochem. Biophys. 369, 197-207.

Tonks, N.K. (2005). Redox redux: revisiting PTPs and the control of cell signaling. Cell 121, 667-670.

Tonks, N.K. and Neel, B.G. (2001). Combinatorial control of the specificity of protein tyrosine phosphatases. Curr. Opin. Cell Biol. 13, 182-195.

Tyrrell, R.M. (1996). Activation of mammalian gene expression by the UV component of sunlight - from models to reality. Bioessays 18, 139-148.

Valencia, A. and Kochevar, I.E. (2006). Ultraviolet A induces apoptosis via reactive oxygen species in a model for SmithLemli-Opitz syndrome. Free Radic. Biol. Med. 40, 641-650.

van Montfort, R.L., Congreve, M., Tisi, D., Carr, R., and Jhoti, H. (2003). Oxidation state of the active-site cysteine in protein tyrosine phosphatase 1B. Nature 423, 773-777.

Received May 23, 2006; accepted July 19, 2006 